\title{
Novel Protein-Repellent and Antibacterial Resins and Cements to Inhibit Lesions and Protect Teeth
}

\author{
Li Cao, ${ }^{1}$ Junling Wu, ${ }^{2,3}$ Qiang Zhang, ${ }^{4}$ Bashayer Baras, ${ }^{3}$ Ghalia Bhadila, ${ }^{3}$ Yuncong Li, ${ }^{3,5}$ \\ Mary Anne S. Melo, ${ }^{3}$ Michael D. Weir, ${ }^{3}$ Yuxing Bai $\mathbb{D}^{1},{ }^{1}$ Ning Zhang ${ }^{\mathbb{D}},{ }^{1,3}$ \\ and Hockin H. K. Xu $\mathbb{D D}^{3,6,7}$ \\ ${ }^{1}$ Department of Orthodontics, School of Stomatology, Capital Medical University, Beijing, China \\ ${ }^{2}$ Department of Prosthodontics, School of Stomatology, Shandong University, Shandong Provincial Key Laboratory of Oral \\ Tissue Regeneration, Jinan 250012, China \\ ${ }^{3}$ Department of Advanced Oral Sciences and Therapeutics, University of Maryland Dental School, Baltimore, MD 21201, USA \\ ${ }^{4}$ Oral Implantology Center, Jinan Stomatological Hospital, Jinan 250001, China \\ ${ }^{5}$ Clinical Research Center of Shaanxi Province for Dental and Maxillofacial Diseases, Key Laboratory of Shaanxi Province for \\ Craniofacial Precision Medicine Research, College of Stomatology, Xi'an Jiaotong University, Xi'an, Shaanxi 710004, China \\ ${ }^{6}$ Center for Stem Cell Biology \& Regenerative Medicine, University of Maryland School of Medicine, Baltimore, MD 21201, USA \\ ${ }^{7}$ Marlene and Stewart Greenebaum Cancer Center, University of Maryland School of Medicine, Baltimore, MD 21201, USA
}

Correspondence should be addressed to Ning Zhang; dentistzhang112@163.com

Received 15 December 2018; Revised 9 May 2019; Accepted 31 May 2019; Published 2 July 2019

Academic Editor: Marta Fernández-García

Copyright (c) $2019 \mathrm{Li}$ Cao et al. This is an open access article distributed under the Creative Commons Attribution License, which permits unrestricted use, distribution, and reproduction in any medium, provided the original work is properly cited.

\begin{abstract}
Orthodontic treatment is increasingly popular as people worldwide seek esthetics and better quality of life. In orthodontic treatment, complex appliances and retainers are placed in the patients' mouths for at least one year, which often lead to biofilm plaque accumulation. This in turn increases the caries-inducing bacteria, decreases the $\mathrm{pH}$ of the retained plaque on an enamel surface, and causes white spot lesions (WSLs) in enamel. This article reviews the cutting-edge research on a new class of bioactive and therapeutic dental resins, cements, and adhesives that can inhibit biofilms and protect tooth structures. The novel approaches include the use of protein-repellent and anticaries polymeric dental cements containing 2-methacryloyloxyethyl phosphorylcholine (MPC) and dimethylaminododecyl methacrylate (DMAHDM); multifunctional resins that can inhibit enamel demineralization; protein-repellent and self-etching adhesives to greatly reduce oral biofilm growth; and novel polymethyl methacrylate resins to suppress oral biofilms and acid production. These new materials could reduce biofilm attachment, raise local biofilm $\mathrm{pH}$, and facilitate the remineralization to protect the teeth. This novel class of dental resin with dual benefits of antibacterial and protein-repellent capabilities has the potential for a wide range of dental and biomedical applications to inhibit bacterial infection and protect the tissues.
\end{abstract}

\section{Introduction}

Orthodontic treatment is increasingly more popular as it can improve the facial esthetics, reduce the occurrence of dental diseases and injuries, enhance the oral functions, correct malocclusion, and minimize the psychosocial problems associated with poor dental and facial appearance. Complex appliances and retainers will be placed in the patients' mouths for at least one year, which may facilitate the plaque aggregation despite good oral hygiene [1]. With the increase of plaque accumulation, the level of caries-inducing bacteria, especially Streptococcus mutans, is elevated, and the $\mathrm{pH}$ of the retained plaque on the enamel surface adjacent to the orthodontic brackets is decreased. This in turn hinders the remineralization process and causes decalcification [2-6]. The first clinical evidence of demineralization in tooth enamel is 
seen as white spot lesions (WSLs), which are defined as the "subsurface enamel porosity from carious demineralization" that presents as "a milky white opacity" $[1-3,7-10]$. The incidence of WSLs in fixed orthodontic treatments is as high as $60.9 \%$, and the demineralization can become noticeable around the brackets as early as 4 weeks after the beginning of multibracket appliance treatment $[1,10]$.

Several methods were investigated to inhibit WSLs, such as educating and motivating the patient, mechanical plaque control and removal, modifying diet (low carbohydrate), and treating with topical fluoride [9-11]. However, these strategies require good long-term patient compliance and therefore are unreliable, especially in children and teenagers [11-13]. Consequently, novel preventive measures that do not rely on patient compliance need to be developed to prevent WSLs.

One promising approach is the development of antibacterial and protein-repellent materials [11, 14-17]. Quaternary ammonium methacrylates (QAMs) have been incorporated into dental resins to inhibit bacterial growth and plaque formation because of their excellent antibacterial potency [14-17]. Salivary proteins in the mouth can adhere to a clean polymer surface, providing anchor points for bacteria attachment, which is the first step in biofilm formation $[18,19]$. Accordingly, efforts were made to develop novel protein-repellent dental materials to prevent the adsorption of proteins from the acquired pellicle [11, 20, 21]. Recently, protein-repellent dental cements, adhesives, and methacrylate resins were developed for the first time to repel bacterial adhesion, decrease acid production, and protect tooth structures. This article reviews the new generation of nanostructured, bioactive, and therapeutic dental materials with protein-repellent and anticaries properties.

\section{Antibacterial and Protein-Repellent Orthodontic Cement to Inhibit WSLs}

Fixed orthodontic appliances contribute to the adhesion of oral bacteria due to their complex design and irregular surfaces. These features limit the naturally occurring selfcleaning mechanisms and restrict proper preventive measures, thus resulting in enamel demineralization $[1,2]$. Indeed, Lucchese and Gherlone [1] showed that the levels of acidogenic bacteria, such as Streptococcus mutans and lactobacilli, increased significantly in orthodontic patients, leading to WSLs around the orthodontic appliances. These lesions, which are characterized by their opacity, mineral loss, and decrease of fluorescence radiance, were commonly seen on the buccal surfaces of the teeth, around the brackets, especially in the gingival area $[1,2]$.

To effectively inhibit the prevalence of WSLs, the most important strategy is to prevent demineralization and biofilm formation [9]. Resin-modified glass ionomer cements (RMGIs) have been used for bracket-bonding cements due to their fluoride- (F-) releasing capabilities and acceptable bond strengths [11]. However, researchers found that RMGIs could accumulate more bacteria due to their relatively rough surfaces, high-surface free energy, and polarity $[22,23]$. In addition, RMGIs were unable to change the low-pH environment, which hindered the remineralization

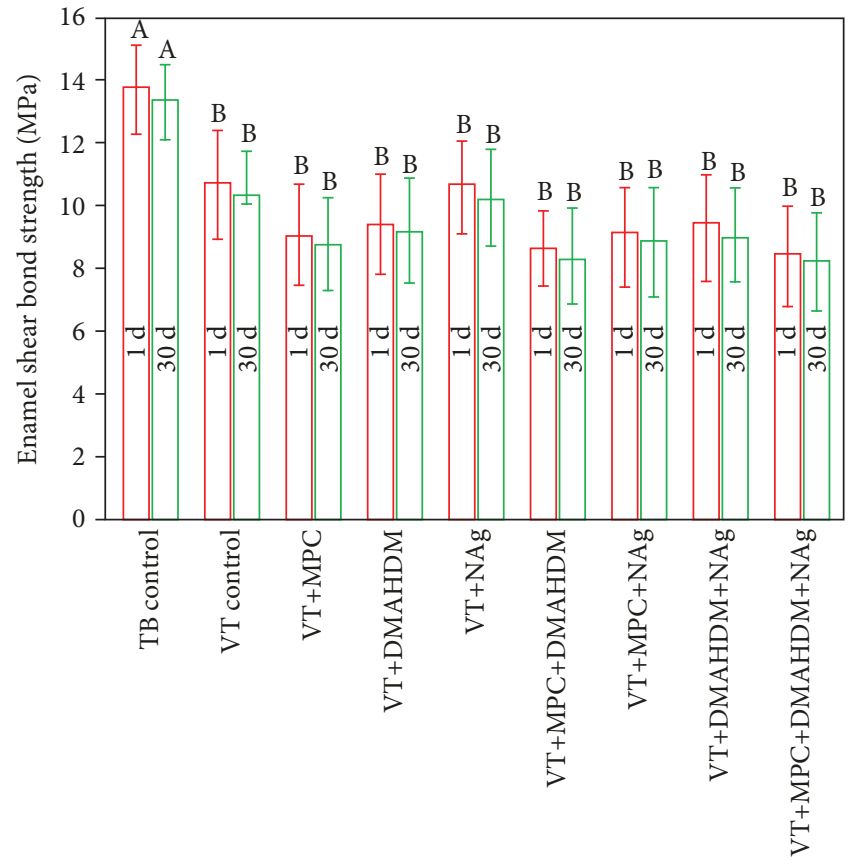

FIgURE 1: Enamel shear bond strengths (SBS) (mean $\pm \mathrm{sd} ; n=10$ ). Incorporating $3 \% \mathrm{MPC}+1.5 \%$ DMAHDM $+0.1 \% \mathrm{NAg}$ into VT did not adversely affect the SBS, compared to VT control $(p>0.1)$. Water aging for $30 \mathrm{~d}$ had no significant effect on SBS, compared to those at $1 \mathrm{~d}(p>0.1)$. Bars with dissimilar letters indicate values that are significantly different from each other $(p<0.05)$. (Adapted from reference [38], with permission).

[24]. Therefore, it would be beneficial to add antimicrobial agents into RMGIs to inhibit protein adsorption, diminish biofilm adhesion, reduce acid production, and thereby prevent or minimize WSLs.

Previous studies incorporated QAMs into dental materials because they reduced the biofilm growth and viability $[11,15,16,25-27]$. Novel dental materials with 12-methacryloyloxydodecylpyridinium bromide (MDPB), methacryloxylethyl cetyl dimethyl ammonium chloride (DMAE-CB), and cetylpyridinium chloride (CPC), as well as other compositions, effectively hindered bacteria and biofilm growth [28-34]. The antibacterial potency increased with increasing the alkyl chain length (CL) from 3 to 16 , with DMAHDM having CL of 16 showing the strongest bactericidal potency [34]. Another bactericidal agent, nanoparticles of silver (NAg), effectively suppressed a wide range of microorganisms due to $\mathrm{Ag}$ ion release [35].

One drawback of the contact inhibition mechanism is that the antibacterial effect of the QAMs is decreased when a salivary protein pellicle separates the antibacterial polymer surface from the overlaying biofilm [36, 37]. Therefore, dental materials exhibiting the double benefits of proteinrepellent and antibacterial activities are desirable. Recently, Zhang et al. [38] developed a novel bioactive orthodontic cement incorporating 3\% MPC, 1.5\% DMAHDM, and 0.1\% NAg into a commercial RMGI, Vitremer (referred to as VT), for the first time. The enamel shear bond strength (SBS) of the cement was not compromised, when compared to the control $(p>0.1)$, even after 30 days of immersed in 


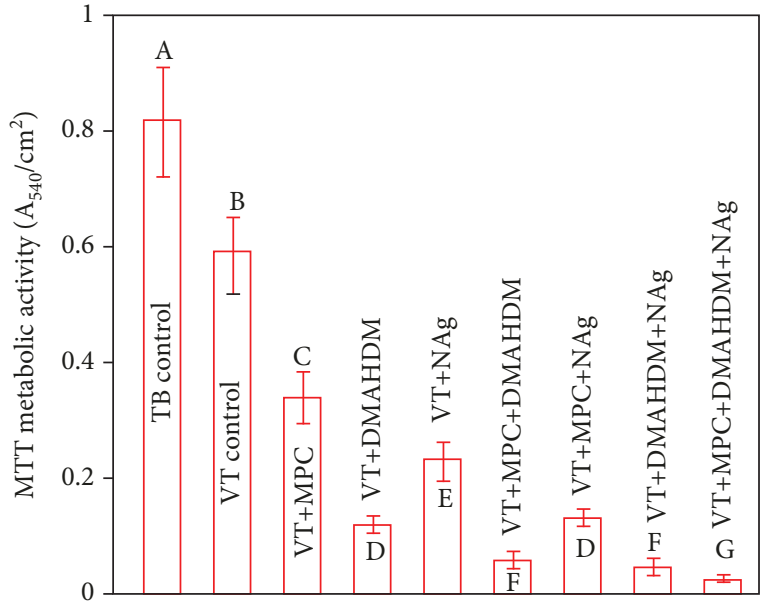

(a)

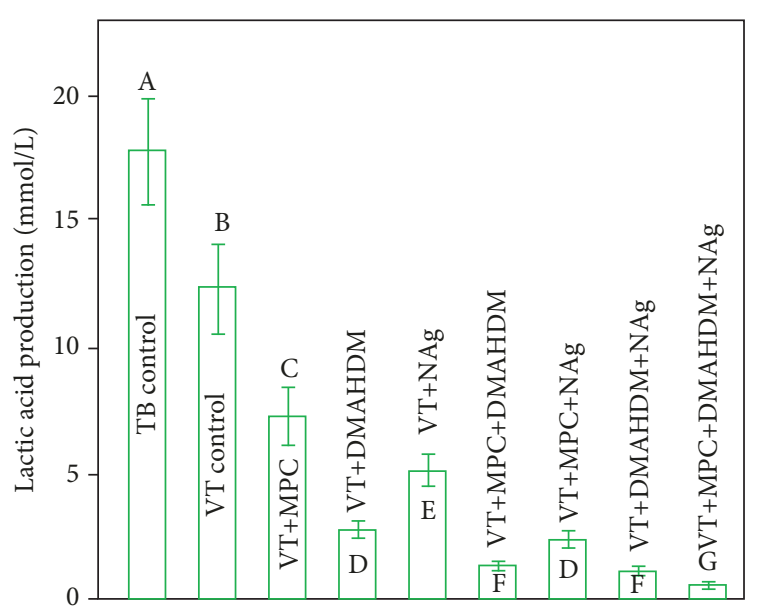

(b)

FIGURe 2: Quantitative viability of the 2-day biofilms on disks: (a) metabolic activity and (b) lactic acid production (mean \pm sd; $n=6$ ). Biofilms on the VT containing 3\% MPC $+1.5 \%$ DMAHDM+0.1\% NAg had the least metabolic activity and lactic acid production among all groups. In each plot, values with dissimilar letters are significantly different from each other $(p<0.05)$. (Adapted from reference [38], with permission).

distilled water at $37^{\circ} \mathrm{C}$ (Figure 1) [38]. Figure 2 illustrates the lactic acid results. VT with 1.5\% DMAHDM alone reduced the lactic acid production to about 1/5 that of VT control, and VT with $0.1 \% \mathrm{NAg}$ alone reduced to nearly $1 / 3$. More dramatically, VT with both DMAHDM and NAg reduced the lactic acid production to $1 / 15$ of that of VT control. A similar trend was observed in the CFU and MTT metabolic activity results, suggesting that DMAHDM and NAg as dual antibacterial agents in RMGI had a multiplying effect in reducing biofilm growth [38]. Representative live/dead bacterial staining images are shown in Figures 3(a)-3(d). VT control was covered with primarily live bacteria (staining green) in Figure 3(a). As illustrated in Figure 3(b), with the addition of MPC, the live bacteria (staining green) were decreased but dead bacteria (staining red) were not noticed, suggesting that MPC could repel the bacteria adsorption but could not kill them. In contrast, in Figure 3(c), VT+DMAHDM+NAg had much more staining of compromised bacteria. In Figure 3(d), $\mathrm{VT}+\mathrm{MPC}+\mathrm{DMAHDM}+\mathrm{NAg}$ had the most red staining and least green staining [38].

In addition, Zhang et al. [38] also found that VT with 3\% MPC+1.5\% DMAHDM and VT with 3\% MPC+0.1\% NAg had lower acid production than those using DMAHDM or NAg without MPC. The acid production was the lowest in $\mathrm{VT}+3 \% \mathrm{MPC}+1.5 \% \mathrm{DMAHDM}+0.1 \% \mathrm{NAg}$, which indicated the synergistic effect of DMAHDM, NAg, and MPC in biofilm inhibition.

These results are related to the mechanism of QAMs and NAg to kill bacteria and the mechanism of MPC to repel protein and bacteria adsorption. QAMs are considered to exhibit the "contact killing" mechanism. The positively charged quaternary amine $\mathrm{N}^{+}$of QAMs can attract the negatively charged cell membrane of bacteria, thus disrupting the bacterial membranes and causing cytoplasmic leakage $[15,16,28]$. The antimicrobial mechanism of NAg was suggested to be Ag ions interacting with vital enzymes of the bacteria, rendering DNA to lose its replication ability, thus leading to cell death [39-41]. Furthermore, studies indicated that NAg had a long distance killing capability and relatively long-term antibacterial activity [42].

The protein-repellent agent MPC is a methacrylate with a phospholipid polar group in the side chain. MPC has been shown to have excellent ability to repel protein adsorption and prevent bacterial adhesion [20, 36]. The mechanism of protein repellency of MPC relates to the structure of phospholipid which contains a hydrophilic head (attracted to water) and hydrophobic tails (repelled by water) [36, 37]. Phospholipids, a major component of all cell membranes, can form lipid bilayers in which the nonpolar tail region faces the inner area and the polar head region faces outward and interacts. Therefore, the MPC polymers are hydrophilic with an abundance of free water but no bound water in the hydrated MPC polymer. While the presence of bound water would cause protein adsorption, the large amount of free water around the hydrated MPC polymer is considered to detach proteins and repel protein adsorption [36, 37, 43]. MPC can greatly reduce the protein adsorption by maxing direct contacts between bacteria and the polymer surface, thus enhancing the antibacterial efficacy of DMAHDM and NAg. In return, DMAHDM and NAg greatly reduces biofilm buildup on the cement surface; this would help to expose more MPC to repel proteins.

Furthermore, the use of triple agents may have a wide applicability not only to dental cements but also to other biomedical materials and tissue engineering scaffolds. The protein-repellent and antibacterial combination could be highly beneficial to inhibit biofilm growth and prevent infection in the wounds. 


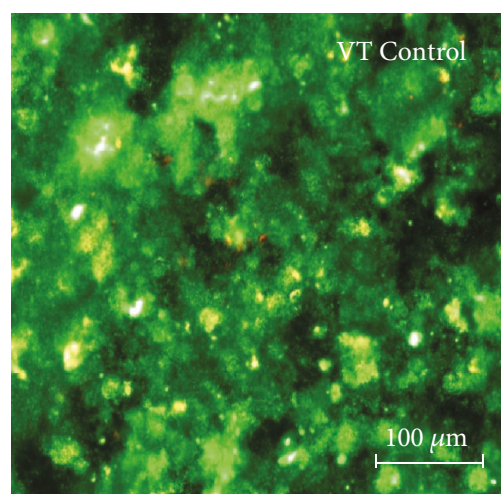

(a)

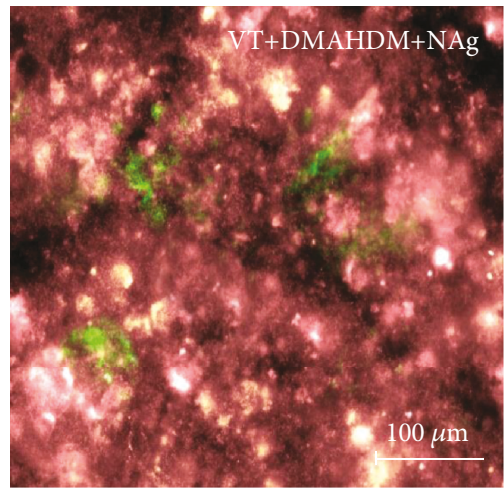

(c)

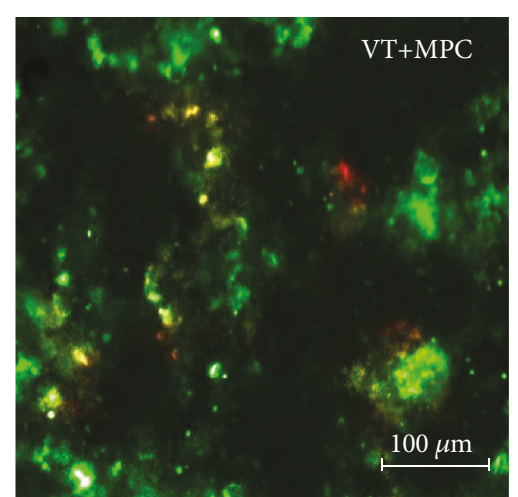

(b)

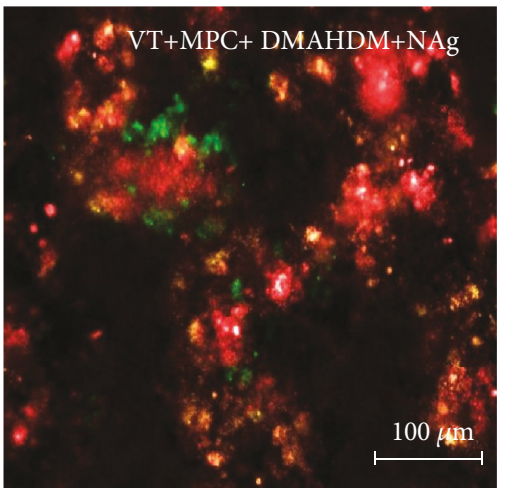

(d)

FIGURE 3: Representative live/dead staining images of 2-day biofilms grown on disks: (a) VT control, (b) VT with 3\% MPC, (c) VT with 1.5\% DMAHDM+0.1\% NAg, and (d) VT with 3\% MPC+1.5\% DMAHDM+0.1\% NAg. Live bacteria were stained green, and compromised bacteria were stained red. When live and dead bacteria were in close proximity or on the top of each other, the staining had yellow or orange colors. The VT with 3\% MPC+1.5\% DMAHDM+0.1\% NAg had less bacterial adhesion, and the biofilms consisted of primarily compromised bacteria. (Adapted from reference [38], with permission).

\section{Multifunctional Cements to Protect Enamel from Demineralization}

During orthodontic treatments, it is difficult to perform oral hygiene procedures on the bonded dental arches. Therefore, more bacteria are accumulated, which can lead to a decrease in $\mathrm{pH}$ that tips the demineralization-remineralization balance toward net mineral loss (demineralization) [2]. RMGIs are preferable to bond the brackets to the teeth because of F-releasing capability, which will reduce enamel demineralization $[11,44]$. However, previous studies indicated that the initial F ion released form RMGIs was high and its concentration in the oral cavity was decreased rapidly over time due to salivary clearance and swallowing [45-48]. Moreover, the long-lasting low $\mathrm{pH}$ around the brackets restricted the remineralization process, so that more $\mathrm{F}$ ions could not produce a better cariostatic effect [24]. Therefore, a new bioactive orthodontic cement that could neutralize the acidic environment, alleviate subsurface enamel demineralization adjacent to brackets, and facilitate the remineralization effect would be highly desirable.

In a previous study, Ma et al. [44] developed a novel orthodontic cement containing protein-repellent MPC, antibacterial monomer DMAHDM, and remineralizing agent nanoparticles of amorphous calcium phosphate (NACP). They measured the average lesion depths (LD) via polarized light microscopy at three distance ranges: from 50 to $150 \mu \mathrm{m}$, from 150 to $250 \mu \mathrm{m}$, and from 250 to $350 \mu \mathrm{m}$, respectively. Among the four groups, the LD of group "RMGI+MPC+DMAHDM+NACP" was the least for all the three distance ranges $(p<0.05)$ [44]. The LD of Transbond XT control was the deepest for the three tested distance ranges $(p<0.05)$, which were $144.06 \pm 24.59 \mu \mathrm{m}$, $148.24 \pm 21.14 \mu \mathrm{m}$, and $157.51 \pm 24.34 \mu \mathrm{m}$, respectively [44]. These results manifest that adhesives, which contain the NACP, do have the cariostatic effect. The results of enamel Knoop microhardness (KHN) also demonstrated the effect of preventing enamel demineralization by using NACP, MPC, and DMAHDM (Figure 4). "RMGI+MPC+DMAHDM+NACP" displayed the highest hardness from 25 to $175 \mu \mathrm{m}$ deep at the three distances, which indicated that incorporating 3\% MPC and 1.5\% DMAHDM into RMGI could give the cement the ability of caries prevention close to the adhesive margin. The enamel hardness of novel cement with NACP was significantly greater than that without NACP; the novel cement with MPC, DMAHDM, and NACP exactly yielded significantly a better demineralization prevention effect when compared 


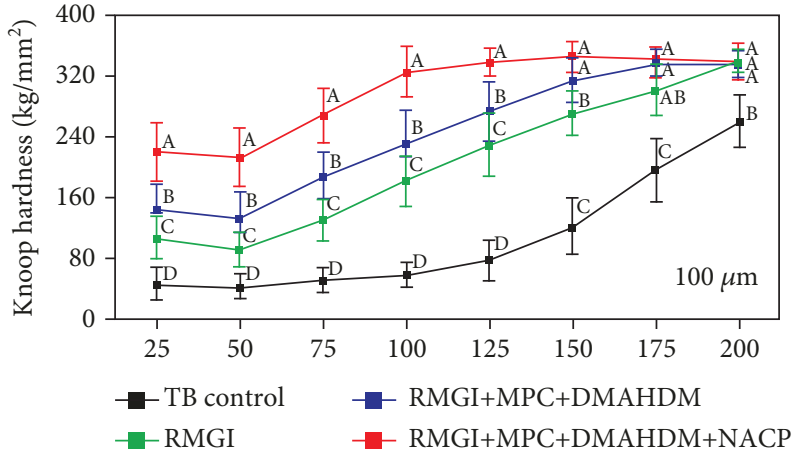

(a)

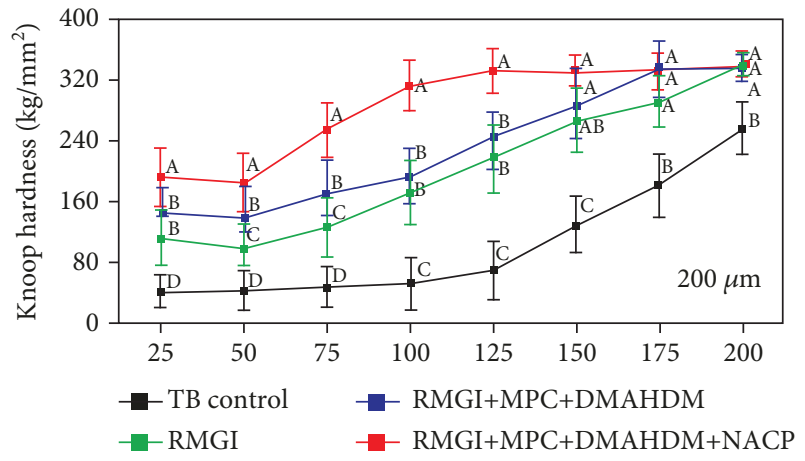

(b)

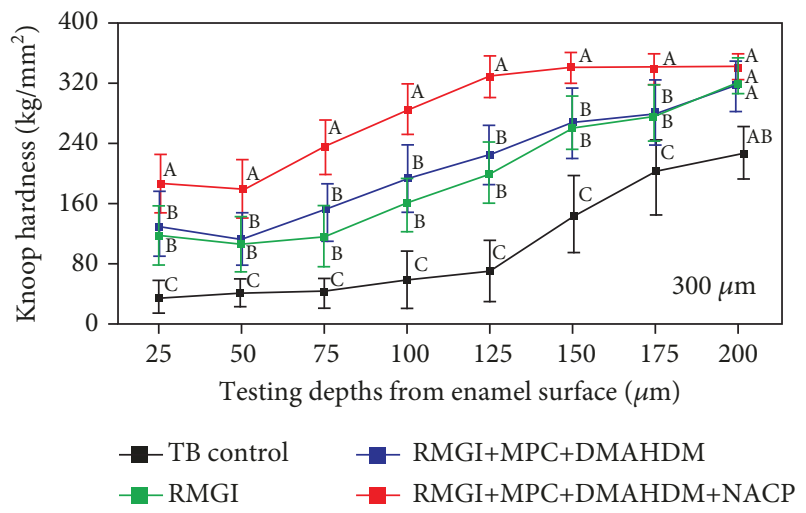

(c)

FIGURE 4: Enamel Knoop microhardness (KHN) values according to materials and testing depths of CSMH analysis (mean \pm sd; $n=12$ ), respectively, at (a) $100 \mu \mathrm{m}$, (b) $200 \mu \mathrm{m}$, and (c), $300 \mu \mathrm{m}$ distance from the margin of cements. Dissimilar letters indicate that values are significantly different with other groups $(p<0.05)$ at each depth. (Adapted from reference [44], with permission).

with a commercial RMGI control [44]. Zhang et al. [49] also added MPC, DMAHDM, NAg, and NACP into RMGI and obtained similar conclusions. They studied the release of $\mathrm{Ca}$ and $\mathrm{P}$ ions at different NACP filler levels and different $\mathrm{pH}$ values. They found that the cement with NACP significantly increased the ion release with the increase of the NACP filler level and with the decrease of $\mathrm{pH}$ from 7 to $4(p<0.05)$ (Figure 5). These results demonstrate that NACP could release $\mathrm{Ca}$ and $\mathrm{P}$ ions at cariogenic $\mathrm{pH}$ when these ions are most needed to combat enamel demineralization [49].

Several studies showed that the NACP nanocomposite achieved $\mathrm{Ca}$ and $\mathrm{P}$ ion releases similar to those of traditional $\mathrm{CaP}$ composites, but the mechanical strength was at least twice as high $[50,51]$. NACP composite could achieve high levels of $\mathrm{Ca}$ and $\mathrm{P}$ ions release at relatively low NACP filler levels because of the high surface area of the nanoparticles of $17.76 \mathrm{~m}^{2} / \mathrm{g}[50,52]$. Indeed, the enamel bond strength was not compromised even if the NACP filler level was $20 \%$ [49]. The $\mathrm{pH}$ was an important factor that affected the demineralization-remineralization balance. Takahashi and Nyvad [53] suggested that the de- and remineralization balance was tilted toward demineralization by the ecological phenomena from bacterial acid production. The bacterial acid-induced adaptation and selection within the microbiota, from the dynamic stability stage to the aciduric stage via the acidogenic stage, could change the environment form being relatively safe to being cariogenic [53-55]. It was suggested that the $\mathrm{pH}$ was lower than 4.5 in the plaque around the brackets $[22,56]$. RMGI-containing NACP was shown to be a "smart material"; it could rapidly increase the $\mathrm{Ca}$ and $\mathrm{P}$ ion release at such a low $\mathrm{pH}$ and neutralize the acidic environment to a safe level of $\mathrm{pH}$ [49]. Therefore, adding NACP to RMGI delivered greater remineralization for enamel lesions than a fluoride-releasing commercial composite, increased the hardness back to normal, and inhibited or minimized WSLs [57]. A further study is still needed to investigate the cytotoxicity and biocompatibility of novel cement and to evaluate biofilm acid reduction and remineralization effects under clinically relevant in vivo conditions.

\section{Bioactive Self-Etch Adhesive to Prevent Enamel Demineralization}

Acid etch techniques are used routinely to bond orthodontic brackets to the teeth [58]. In 1955, Buonocore introduced the phosphoric acid etching technique which has revolutionized and improved the clinical practice of orthodontics $[3,59]$. However, $37 \%$ phosphoric acid etching has several disadvantages, including causing enamel surface roughness, removing irreversibly several microns of the enamel layer, demineralization of the superficial layer of enamel near the brackets and junctions, and enamel fracture and crazing at the time of bracket debonding [58-60]. Indeed, Kim et al. 


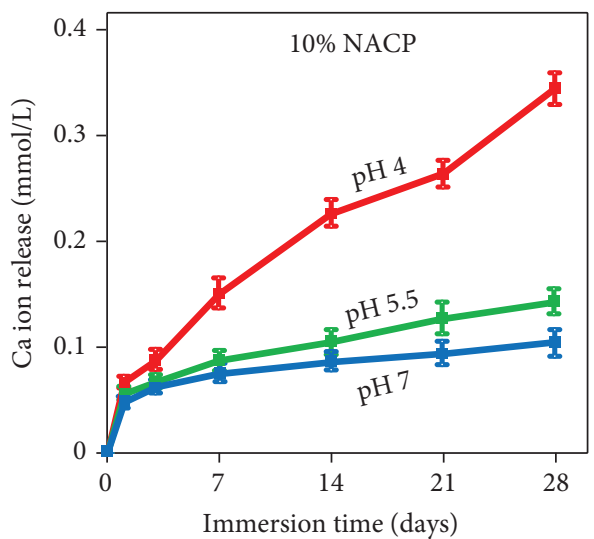

(a)

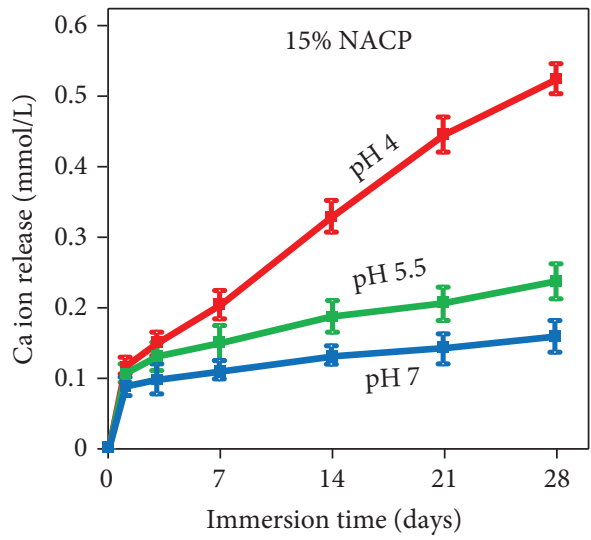

(c)

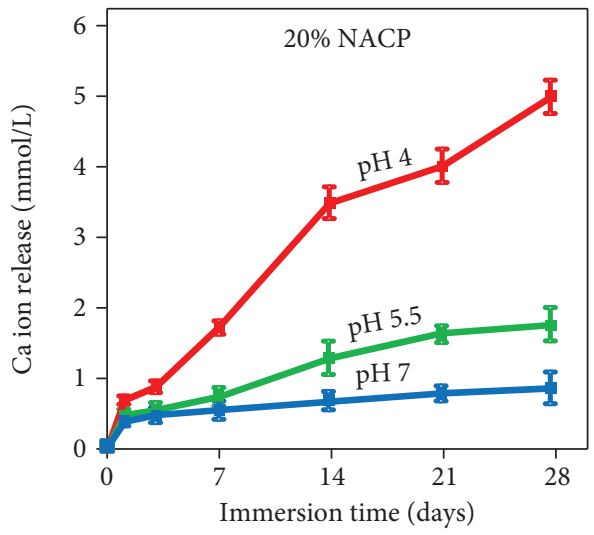

(e)

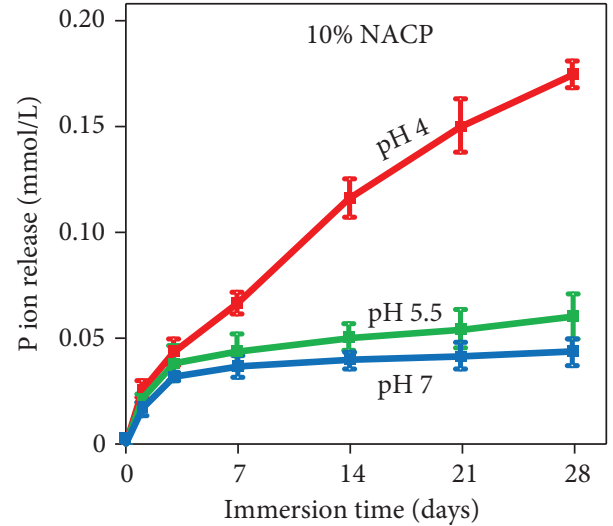

(b)

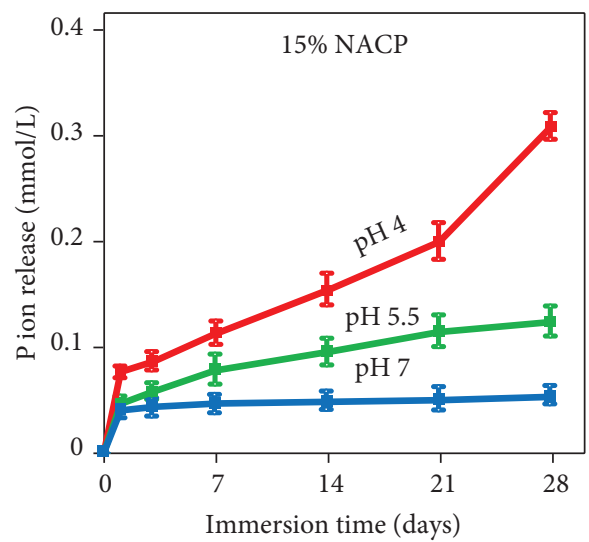

(d)

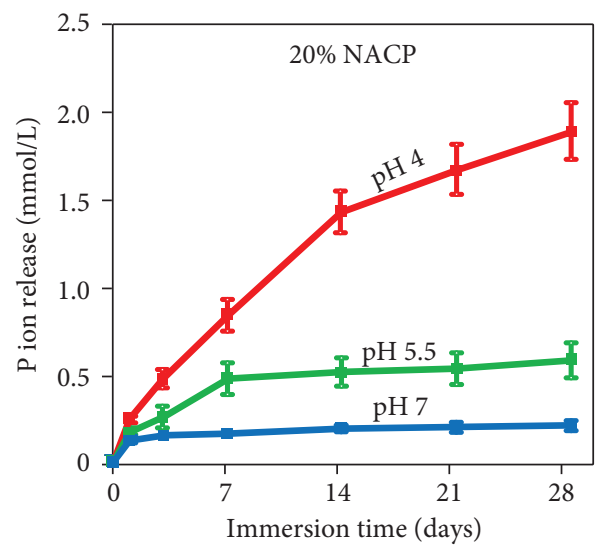

(f)

FIGUre 5: Calcium (Ca) and phosphate $(\mathrm{P})$ ion release (mean $\pm \mathrm{sd} ; n=3$ ) from the VT filled with: (a, b) 10\% NACP, (c, d) 15\% NACP, and $(\mathrm{e}, \mathrm{f}) 20 \%$ NACP. Ion release increased with increasing the immersion time and the NACP filler level. Ion release increased with decreasing the solution $\mathrm{pH}$. (Adapted from reference [49], with permission).

[58] found that using acid etching could cause from 5 up to $10 \mathrm{~mm}$ of enamel loss, which could render the enamel surface more susceptible to demineralization during and after orthodontic treatment.

Several alternative approaches have been undertaken to reduce the adverse effects of the phosphoric acid etching, such as the use of different enamel preparation and adhesive systems [58]. Therefore, self-etching adhesive systems have been used for bracket bonding with the advantages of elimi- nating the need for a separate etching step, allowing for the simultaneous etching and adhesive penetration and forming a protective layer on the enamel surface. This avoids the negative effects of the traditional method with a separate acid etching step on enamel [61].

Adhesion of $S$. mutans to surfaces in the mouth will support the subsequent attachment and growth of other bacterial species, ultimately forming a microecosystem known as a biofilm [62]. At the tooth surface around the brackets, oral 


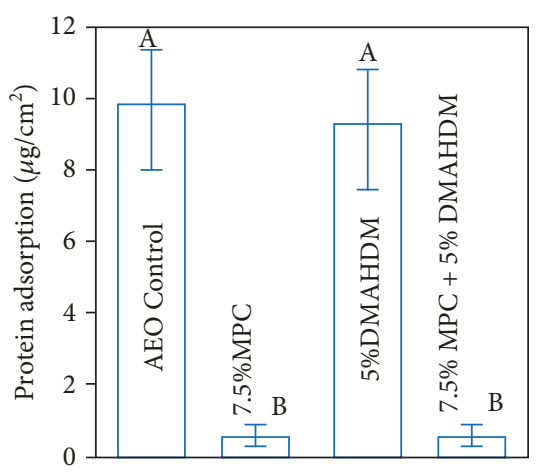

(a)

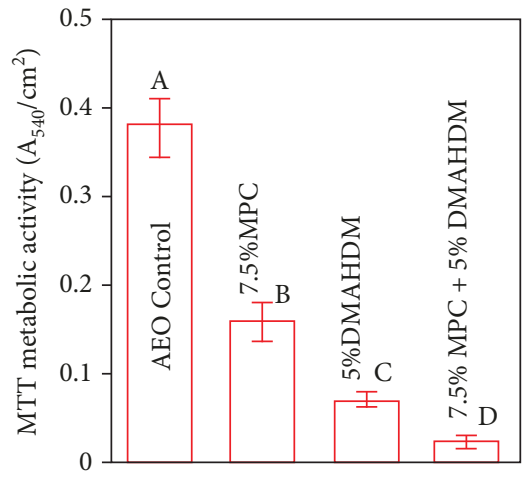

(b)

FIGURE 6: Protein adsorption and biofilm metabolic activity. (a) Protein adsorption onto self-etch adhesive (mean \pm sd; $n=6$ ). AEO with $7.5 \%$ MPC+5\% DMAHDM had much less protein adsorption, which was about $5 \%$ that of AEO control $(p<0.05)$. Bars with dissimilar letters indicate values that are significantly different from each other $(p<0.05)$. (b) Biofilm metabolic activity on disks cultured for 2 days (mean $\pm \mathrm{sd} ; n=6)$. Metabolic activity of biofilms on AEO with $7.5 \%$ MPC+5\% DMAHDM was reduced to $5 \%$ that of AEO control $(p<0.05)$. Values with dissimilar letters are significantly different from each other $(p<0.05)$. (Adapted from reference [63], with permission).

biofilms can produce acids and cause WSLs or caries. Although dental plaque biofilm cannot be eliminated, it may be possible to reduce the pathogenic impact of the biofilm at the margin of the brackets by rendering the adhesive protein-repellent and antibacterial properties to suppress biofilm attachment and buildup [62]. It is highly desired to develop a new antibacterial self-etching adhesive to combat biofilms and WSLs.

In a previous study, Wang et al. [63] mixed MPC and DMAHDM into a self-etch adhesive (Adper Easy One, $3 \mathrm{M}$, St. Paul, MN, USA; referred to as AEO) to repel protein adsorption and decrease bacteria accumulation. In their study, the self-etch adhesive with 7.5\% MPC had much less bacterial attachment and reduced the protein adsorption to only 5\% that of control (Figure 6(a)). Adding either 5\% DMAHDM or $7.5 \%$ MPC alone into AEO reduced the metabolic activity to nearly $17 \%$ and $33 \%$ of that of AEO control, respectively. More dramatically, biofilms on the adhesive containing both 7.5\% MPC and 5\% DMAHDM together had the lowest metabolic activity, which was only $5 \%$ of that of AEO control (Figure 6(b)) [63].

Based on these results, Wang et al. [63] suggested that there was a synergistic effect of MPC and DMAHDM in the adhesive on antibiofilm properties. Quaternary ammonium compounds, which were positively charged, could bind to the negatively charged cell wall components, cause the leakage of the cytoplasmatic material, and finally lead to the lysis of the bacterial cells [31]. The antibacterial potency increased with increasing CL from 3 to 16 and decreased with CL further increasing to 18 [34]. DMAHDM with a chain length of 16 had the most potent antibacterial efficacy among all the QAMs tested [34]. The addition of MPC could dramatically enhance the antibacterial efficacy of DMAHDM by repelling the proteins on the adhesive resin to facilitate the mechanism of "contact killing" [64]. Therefore, the synergistic effect of MPC and DMAHDM was demonstrated not only in orthodontic cements but also in dental adhesives.

Another important issue is that an adequate bond strength is necessary for the fixed appliance therapy to be successful [61]. However, the bond strength also needs to be low enough to escape enamel damage during bracket debonding. Bishara et al. [59] suggest that enamel fracture and crazing existed at the time of bracket debonding, especially with ceramic brackets. As a result, orthodontists prefer bond failure at the bracket-adhesive interface to within the adhesive. Lamper et al. [65] found that, if the bond strength was lower than $12 \mathrm{MPa}$, little enamel damage was noticed; however, the risk would increase 14-fold if the strength was over $12 \mathrm{MPa}$. Reynolds et al. [66] suggested that the appropriate shear bonding strength for orthodontic cements was approximately 8 to $9 \mathrm{MPa}$, which was high enough to prevent the brackets from falling off the surface of the teeth, while avoiding enamel damage during the debonding process at the completion of the orthodontic treatment. The results of Wang et al. [63] showed that the enamel shear bond strength of the self-etch group containing MPC and DMAHDM was 9-10 MPa, which is clinically acceptable. Their research suggested that adding MPC and DMAHDM into the self-etch adhesive exhibited excellent antibacterial and proteinrepellent effect without compromising the bond strength of the brackets.

\section{Protein-Repellent and Antibacterial PMMA Resin to Suppress Biofilms}

In addition to photopolymerization, heat cure is used in dentistry to increase the polymerization conversion and enhance the mechanical properties. Heat-cured resins are commonly used in orthodontics for making complicated functional appliances to correct severe skeletal class II and III malocclusions of preadolescent patients and for fabricating retainers to keep the esthetic results of orthodontic treatment $[1,67,68]$. The complex designing of appliances and retainers may prevent effective cleaning, thus inducing caries, periodontal diseases, and even denture-induced stomatitis in acrylate resin wearers $[1,69,70]$. Moreover, Takahashi et al. [21] suggested that polymethyl methacrylate- (PMMA-) based acrylic resins had a relatively high 


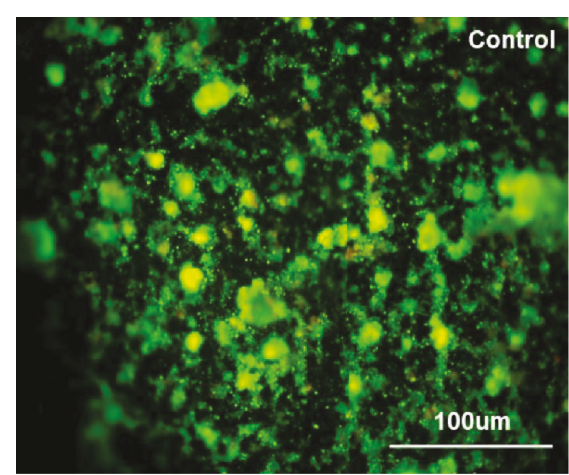

(a)

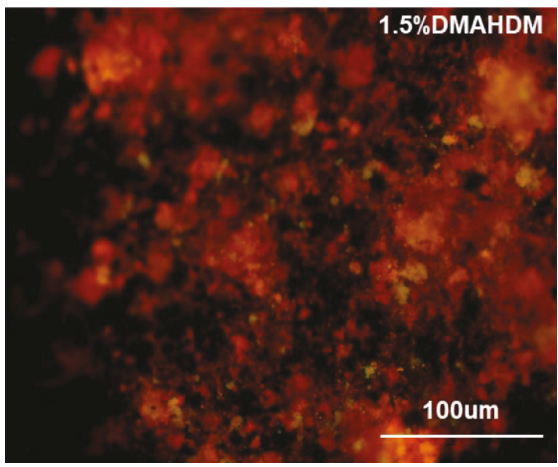

(c)

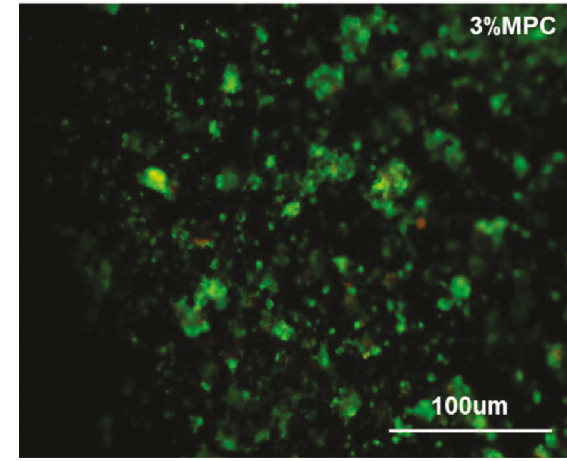

(b)

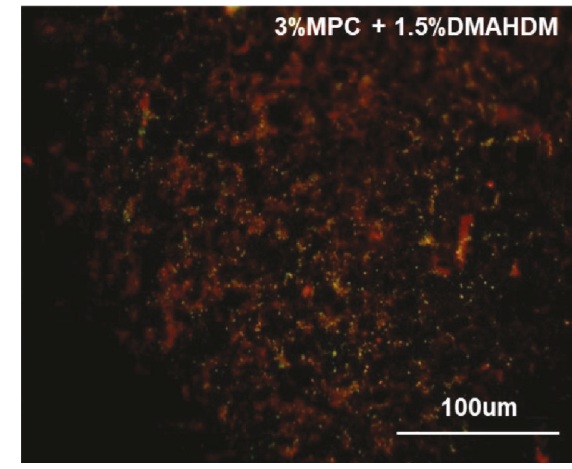

(d)

Figure 7: Representative live/dead staining images of biofilms adherent on PMMA discs cultured for 2 days: (a) control group, (b) 3\% MPC group, (c) 1.5\% DMAHDM group, and (d) 3\% MPC+1.5\% DMAHDM group. The live bacteria were stained green, and the dead bacteria were stained red. When live and dead bacteria were in close proximity or on the top of each other, the staining had yellow or orange colors. (Adapted from reference [75], with permission).

water absorption capacity and were prone to dental plaque accumulation. Because the appliances and retainers would wear at least 2 years in the patient's mouth, so the accumulation of biofilms and plaque on the resin surfaces could create unfavorable odors and further accelerate oral bacteria-related infection [67]. Although adequate cleaning of the appliances and retainers is imperative for the prevention of bacterial related diseases, it is more beneficial and necessary to develop an antibacterial resin surface. Antimicrobial agents were added into dental materials, which can be divided into two classes: released and nonreleased materials [31]. However, there were several disadvantages of using released antibacterial agents, including compromising mechanical properties of the carrier material over time, short-term effectiveness, and possible toxicity if the release was not properly controlled [71-73]. In contrast, polymeric antibacterial agents, which were nonvolatile and chemically stable, exhibited a stronger antimicrobial effect by interacting with and disrupting bacterial cell membranes $[31,74]$.

In another study, Cao et al. [75] combined MPC and DMAHDM into the PMMA-based acrylic resin to decrease the biofilm amounts and metabolic activity. The MPC mass fraction incorporated into acrylic resin was 3\%, which was selected to produce the strongest protein repellency while not compromising the mechanical properties. Similarly, the maximum amount of DMAHDM in the PMMA resin was determined to be $1.5 \%$. The flexural strength of the compos- ite containing 3\% MPC and 1.5\% DMAHDM was $71 \mathrm{MPa}$, similar to $73 \mathrm{MPa}$ of a commercial composite without antibacterial or protein-repellent functions $(p>0.1)$. The composite containing 3\% MPC and 1.5\% DMAHDM had an elastic modulus of $2020 \mathrm{MPa}$, similar to $2142 \mathrm{MPa}$ of the commercial composite $(p>0.1)$ [75]. Using human saliva as inoculum, dental plaque microcosm biofilms were grown on the resins for two days to form a relatively mature biofilm. The representative live/dead staining photos of the 2-day biofilms on acrylic resins are illustrated in Figure 7. There were much less, but alive, bacteria via MPC (green staining) which reduced bacteria attachment by means of protein repellence, and there were substantial amounts of compromised bacteria (red staining) via DMAHDM which killed the bacteria by way of contact inhibition. Furthermore, the acrylic resin with $3 \%$ MPC+1.5\% DMAHDM had the least bacterial adhesion, and the biofilms consisted of primarily dead bacteria with red staining, which demonstrated the enhanced antibacterial efficacy when double agents (protein-repellant MPC+antibacterial DMAHDM) were used in the same acrylate resin [75].

The new bioactive PMMA resin incorporating double agents of MPC and DMAHDM greatly reduced protein adsorption and biofilm growth, which could decrease the incidence of caries, periodontal diseases, and acrylic resinrelated stomatitis. Their combined use may be beneficial not only to dental materials but also to other biomedical materials and tissue engineering fields, such as a bone cement 
in total joint arthroplasty, spinal surgery, fracture repair, and limb-sparing procedures [76]. Further investigations are needed to determine whether and how the strength and the capabilities of the antibiofilm and protein repellence of the new PMMA resin would decrease after long-term aging in experiments simulating the oral environment.

\section{Conclusions}

This article represents a cutting edge review on the development of a new generation of antibacterial and proteinrepellent dental cements and adhesives with bioactive and therapeutic properties to inhibit biofilms, promote remineralization, and protect the tooth structures. Compared with traditional materials, the new class of bioactive materials had excellent antibacterial and protein-repellent efficacy in various systems including orthodontic cements, self-etch adhesives, and polymethyl methacrylate resin-based appliances and retainers. These new materials incorporated novel agents, including antibacterial QAMs and NAg, proteinrepellent agent MPC, and remineralization filler NACP. They inhibited oral bacterial pathogens, repelled protein adsorption, and promoted remineralization to effectively combat WSLs. This novel class of dental materials with antibacterial and protein-repellent activities provided the much-needed therapeutic capabilities that are lacking in traditional materials. These novel materials and methods are expected to have a wide range of applicability to other dental and biomedical materials to acquire antibacterial, protein-repellent, and therapeutic functions.

\section{Disclosure}

Li Cao, Junling Wu, and Qiang Zhang are co-first author.

\section{Conflicts of Interest}

The authors declare no conflict of interest.

\section{Acknowledgments}

This study was supported by Beijing Hospitals' Program (ZYLX201703) (YB); National Key R\&D Program of China (2017YFC1104304) (YB); National Natural Science Foundation (NSF) of China (81671032) (JLW); University of Maryland, Baltimore County seed grant (HX); and School of Dentistry, University of Maryland bridge fund (HX).

\section{References}

[1] A. Lucchese and E. Gherlone, "Prevalence of white-spot lesions before and during orthodontic treatment with fixed appliances," European Journal of Orthodontics, vol. 35, no. 5, pp. 664-668, 2013.

[2] D. Sundararaj, S. Venkatachalapathy, A. Tandon, and A. Pereira, "Critical evaluation of incidence and prevalence of white spot lesions during fixed orthodontic appliance treatment: a meta-analysis," Journal of International Society of Preventive and Community Dentistry, vol. 5, no. 6, pp. 433-439, 2015.
[3] B. Ogaard, "Prevalence of white spot lesions in 19-year-olds: a study on untreated and orthodontically treated persons 5 years after treatment," American Journal of Orthodontics and Dentofacial Orthopedics, vol. 96, no. 5, pp. 423-427, 1989.

[4] A. Diamanti-Kipioti, F. A. Gusberti, and N. P. Lang, "Clinical and microbiological effects of fixed orthodontic appliances," Journal of Clinical Periodontology, vol. 14, no. 6, pp. 326333, 1987.

[5] J. W. Balenseifen and J. V. Madonia, "Study of dental plaque in orthodontic patients," Journal of Dental Research, vol. 49, no. 2, pp. 320-324, 1970.

[6] R. M. Boyar, A. Thylstrup, L. Holmen, and G. H. Bowden, "The microflora associated with the development of initial enamel decalcification below orthodontic bands in vivo in children living in a fluoridated-water area," Journal of Dental Research, vol. 68, no. 12, pp. 1734-1738, 1989.

[7] E. Tufekci, J. S. Dixon, J. C. Gunsolley, and S. J. Lindauer, "Prevalence of white spot lesions during orthodontic treatment with fixed appliances," The Angle Orthodontist, vol. 81, no. 2, pp. 206-210, 2011.

[8] K. Lopatiene, M. Borisovaite, and E. Lapenaite, "Prevention and treatment of white spot lesions during and after treatment with fixed orthodontic appliances: a systematic literature review," Journal of Oral and Maxillofacial Research, vol. 7, no. 2, pp. e1-e8, 2016.

[9] M. Khoroushi and M. Kachuie, "Prevention and treatment of white spot lesions in orthodontic patients," Contemporary Clinical Dentistry, vol. 8, no. 1, pp. 11-19, 2017.

[10] M. Enaia, N. Bock, and S. Ruf, "White-spot lesions during multibracket appliance treatment: a challenge for clinical excellence," American Journal of Orthodontics and Dentofacial Orthopedics, vol. 140, no. 1, pp. e17-e24, 2011.

[11] N. Zhang, C. Chen, M. D. Weir, Y. Bai, and H. H. K. Xu, “Antibacterial and protein-repellent orthodontic cement to combat biofilms and white spot lesions," Journal of Dentistry, vol. 43, no. 12, pp. 1529-1538, 2015.

[12] B. J. Maxfield, A. M. Hamdan, E. Tüfekçi, B. Shroff, A. M. Best, and S. J. Lindauer, "Development of white spot lesions during orthodontic treatment: perceptions of patients, parents, orthodontists, and general dentists," American Journal of Orthodontics and Dentofacial Orthopedics, vol. 141, no. 3, pp. 337-344, 2012.

[13] J. A. Chapman, W. E. Roberts, G. J. Eckert, K. S. Kula, and C. González-Cabezas, "Risk factors for incidence and severity of white spot lesions during treatment with fixed orthodontic appliances," American Journal of Orthodontics and Dentofacial Orthopedics, vol. 138, no. 2, pp. 188-194, 2010.

[14] E. Sungurtekin-Ekci, D. Ozdemir-Ozenen, S. Duman, I. C. Acuner, and N. Sandalli, "Antibacterial surface properties of various fluoride-releasing restorative materials in vitro," Journal of Applied Biomaterials \& Functional Materials, vol. 13, pp. e169-e173, 2015.

[15] S. Imazato, Y. Kinomoto, H. Tarumi, S. Ebisu, and F. R. Tay, "Antibacterial activity and bonding characteristics of an adhesive resin containing antibacterial monomer MDPB," Dental Materials, vol. 19, no. 4, pp. 313-319, 2003.

[16] S. Imazato, "Antibacterial properties of resin composites and dentin bonding systems," Dental Materials, vol. 19, no. 6, pp. 449-457, 2003.

[17] N. Hiraishi, C. K. Y. Yiu, N. M. King, and F. R. Tay, "Effect of chlorhexidine incorporation into a self-etching primer on 
dentine bond strength of a luting cement," Journal of Dentistry, vol. 38, no. 6, pp. 496-502, 2010.

[18] R. M. Donlan and J. W. Costerton, "Biofilms : survival mechanisms of clinically relevant microorganisms," Clinical Microbiology Reviews, vol. 15, no. 2, pp. 167-193, 2002.

[19] X. Gao, S. Jiang, D. Koh, and C. Y. S. Hsu, "Salivary biomarkers for dental caries," Periodontology 2000, vol. 70, no. 1, pp. 128$141,2016$.

[20] J. Sibarani, M. Takai, and K. Ishihara, "Surface modification on microfluidic devices with 2-methacryloyloxyethyl phosphorylcholine polymers for reducing unfavorable protein adsorption," Colloids and Surfaces B: Biointerfaces, vol. 54, no. 1, pp. 88-93, 2007.

[21] N. Takahashi, F. Iwasa, Y. Inoue, H. Morisaki, K. Ishihara, and K. Baba, "Evaluation of the durability and antiadhesive action of 2-methacryloyloxyethyl phosphorylcholine grafting on an acrylic resin denture base material," The Journal of Prosthetic Dentistry, vol. 112, no. 2, pp. 194-203, 2014.

[22] H. Badawi, R. D. Evans, M. Wilson, D. Ready, J. H. Noar, and J. Pratten, "The effect of orthodontic bonding materials on dental plaque accumulation and composition in vitro," Biomaterials, vol. 24, no. 19, pp. 3345-3350, 2003.

[23] B.-S. Lim, S. J. Lee, J. W. Lee, and S. J. Ahn, "Quantitative analysis of adhesion of cariogenic streptococci to orthodontic raw materials," American Journal of Orthodontics and Dentofacial Orthopedics, vol. 133, no. 6, pp. 882-888, 2008.

[24] A. Derks, C. Katsaros, J. E. Frencken, M. A. van't Hof, and A. M. Kuijpers-Jagtman, "Caries-inhibiting effect of preventive measures during orthodontic treatment with fixed appliances. A systematic review," Caries Research, vol. 38, no. 5, pp. 413420, 2004.

[25] J. M. Antonucci, D. N. Zeiger, K. Tang, S. Lin-Gibson, B. O. Fowler, and N. J. Lin, "Synthesis and characterization of dimethacrylates containing quaternary ammonium functionalities for dental applications," Dental Materials, vol. 28, no. 2, pp. 219-228, 2012.

[26] X. Xu, Y. Wang, S. Liao, Z. T. Wen, and Y. Fan, "Synthesis and characterization of antibacterial dental monomers and composites," Journal of Biomedical Materials Research Part B: Applied Biomaterials, vol. 100B, no. 4, pp. 1151-1162, 2012.

[27] X. Shi, H. B. Lu, J. Mao, and S. Q. Gong, "Current status and further prospects of dental resin-based materials with antibacterial properties," Zhonghua Kou Qiang Yi Xue Za Zhi, vol. 51, no. 9, pp. 566-569, 2016.

[28] F. Li, J. Chen, Z. Chai et al., "Effects of a dental adhesive incorporating antibacterial monomer on the growth, adherence and membrane integrity of Streptococcus mutans," Journal of Dentistry, vol. 37, no. 4, pp. 289-296, 2009.

[29] N. Hirose, R. Kitagawa, H. Kitagawa et al., "Development of a cavity disinfectant containing antibacterial monomer MDPB," Journal of Dental Research, vol. 95, no. 13, pp. 1487-1493, 2016.

[30] S. Imazato, "Bio-active restorative materials with antibacterial effects: new dimension of innovation in restorative dentistry," Dental Materials Journal, vol. 28, no. 1, pp. 11-19, 2009.

[31] N. Beyth, I. Yudovin-Farber, R. Bahir, A. J. Domb, and E. I. Weiss, "Antibacterial activity of dental composites containing quaternary ammonium polyethylenimine nanoparticles against Streptococcus mutans," Biomaterials, vol. 27, no. 21, pp. 3995-4002, 2006.
[32] Y. Weng, L. Howard, X. Guo, V. J. Chong, R. L. Gregory, and D. Xie, "A novel antibacterial resin composite for improved dental restoratives," Journal of Materials Science. Materials in Medicine, vol. 23, no. 6, pp. 1553-1561, 2012.

[33] S. Imazato, F. R. Tay, A. V. Kaneshiro, Y. Takahashi, and S. Ebisu, "An in vivo evaluation of bonding ability of comprehensive antibacterial adhesive system incorporating MDPB," Dental Materials, vol. 23, no. 2, pp. 170-176, 2007.

[34] F. Li, M. D. Weir, and H. H. K. Xu, "Effects of quaternary ammonium chain length on antibacterial bonding agents," Journal of Dental Research, vol. 92, no. 10, pp. 932-938, 2013.

[35] C. Fan, L. Chu, H. R. Rawls, B. K. Norling, H. L. Cardenas, and K. Whang, "Development of an antimicrobial resin-a pilot study,” Dental Materials, vol. 27, no. 4, pp. 322-328, 2011.

[36] K. Ishihara, H. Nomura, T. Mihara, K. Kurita, Y. Iwasaki, and N. Nakabayashi, "Why do phospholipid polymers reduce protein adsorption?," Journal of Biomedical Materials Research, vol. 39, no. 2, pp. 323-330, 1998.

[37] K. Ishihara, T. Ueda, and N. Nakabayashi, "Preparation of phospholipid polylners and their properties as polymer hydrogel membranes," Polymer Journal, vol. 22, no. 5, pp. 355-360, 1990.

[38] N. Zhang, M. A. S. Melo, J. M. Antonucci et al., "Novel dental cement to combat biofilms and reduce acids for orthodontic applications to avoid enamel demineralization," Materials, vol. 9, no. 6, p. 413, 2016.

[39] Y. J. Cheng, D. N. Zeiger, J. A. Howarter et al., "In situ formation of silver nanoparticles in photocrosslinking polymers," Journal of Biomedical Materials Research Part B: Applied Biomaterials, vol. 97B, no. 1, pp. 124-131, 2011.

[40] M. Rai, A. Yadav, and A. Gade, "Silver nanoparticles as a new generation of antimicrobials," Biotechnology Advances, vol. 27, no. 1, pp. 76-83, 2009.

[41] W. K. Jung, H. C. Koo, K. W. Kim, S. Shin, S. H. Kim, and Y. H. Park, "Antibacterial activity and mechanism of action of the silver ion in Staphylococcus aureus and Escherichia coli," Applied and Environmental Microbiology, vol. 74, no. 7, pp. 2171-2178, 2008.

[42] J. R. Morones, J. L. Elechiguerra, A. Camacho et al., "The bactericidal effect of silver nanoparticles," Nanotechnology, vol. 16, no. 10, pp. 2346-2353, 2005.

[43] T. Goda, T. Konno, M. Takai, and K. Ishihara, "Photoinduced phospholipid polymer grafting on Parylene film: advanced lubrication and antibiofouling properties," Colloids and Surfaces B: Biointerfaces, vol. 54, no. 1, pp. 67-73, 2007.

[44] Y. Ma, N. Zhang, M. D. Weir, Y. Bai, and H. H. K. Xu, "Novel multifunctional dental cement to prevent enamel demineralization near orthodontic brackets," Journal of Dentistry, vol. 64, pp. 58-67, 2017.

[45] C. D. Lynch, "Summary of: A retrospective, practice-based, clinical evaluation of Fuji IX restorations aged over five years placed in load-bearing cavities," British Dental Journal, vol. 215, no. 6, pp. 290-291, 2013.

[46] E. Paschos, T. Galosi, K. C. Huth, I. Rudzki, A. Wichelhaus, and K. H. Kunzelmann, "Do bonding agents protect the bracket-periphery?-Evaluation by consecutive $\mu \mathrm{CT}$ scans and fluorescence measurements," Clinical Oral Investigations, vol. 19, no. 1, pp. 159-168, 2015.

[47] E. Chatzistavrou, T. Eliades, S. Zinelis, A. E. Athanasiou, and G. Eliades, "Fluoride release from an orthodontic glass ionomer adhesive in vitro and enamel fluoride uptake in vivo," 
American Journal of Orthodontics and Dentofacial Orthopedics, vol. 137, no. 4, pp. 458.e1-458.e8, 2010.

[48] M. Kashani, S. Farhadi, and N. Rastegarfard, "Comparison of the effect of three cements on prevention of enamel demineralization adjacent to orthodontic bands," Journal of Dental Research, Dental Clinics, Dental Prospects, vol. 6, no. 3, pp. 89-93, 2012.

[49] N. Zhang, M. D. Weir, C. Chen, M. A. S. Melo, Y. Bai, and H. H. K. Xu, "Orthodontic cement with protein-repellent and antibacterial properties and the release of calcium and phosphate ions," Journal of Dentistry, vol. 50, pp. 51-59, 2016.

[50] H. H. K. Xu, J. L. Moreau, L. Sun, and L. C. Chow, "Nanocomposite containing amorphous calcium phosphate nanoparticles for caries inhibition," Dental Materials, vol. 27, no. 8, pp. 762-769, 2011.

[51] S. H. Dickens, G. M. Flaim, and S. Takagi, "Mechanical properties and biochemical activity of remineralizing resinbased $\mathrm{Ca}-\mathrm{PO}_{4}$ cements," Dental Materials, vol. 19, no. 6, pp. 558-566, 2003.

[52] H. H. K. Xu, M. D. Weir, L. Sun et al., "Strong nanocomposites with $\mathrm{Ca}, \mathrm{PO}_{4}$, and $\mathrm{F}$ release for caries inhibition," Journal of Dental Research, vol. 89, no. 1, pp. 19-28, 2010.

[53] N. Takahashi and B. Nyvad, "Ecological hypothesis of dentin and root caries," Caries Research, vol. 50, no. 4, pp. 422-431, 2016.

[54] N. Takahashi and B. Nyvad, "The role of bacteria in the caries process : ecological perspectives," Journal of Dental Research, vol. 90, no. 3, pp. 294-303, 2011.

[55] C. Dawes, "What is the critical $\mathrm{pH}$ and why does a tooth dissolve in acid?," Journal of the Canadian Dental Association, vol. 69, no. 11, pp. 722-724, 2003.

[56] S. Rogers, B. Chadwick, and E. Treasure, "Fluoride-containing orthodontic adhesives and decalcification in patients with fixed appliances: a systematic review," American Journal of Orthodontics and Dentofacial Orthopedics, vol. 138, no. 4, pp. 390.e1-390.e8, 2010.

[57] M. D. Weir, L. C. Chow, and H. H. K. Xu, "Remineralization of demineralized enamel via calcium phosphate nanocomposite," Journal of Dental Research, vol. 91, no. 10, pp. 979-984, 2012.

[58] M. J. Kim, B. S. Lim, W. G. Chang, Y. K. Lee, S. H. Rhee, and H. C. Yang, "Phosphoric acid incorporated with acidulated phosphate fluoride gel etchant effects on bracket bonding," The Angle Orthodontist, vol. 75, no. 4, pp. 678-684, 2005.

[59] S. E. Bishara, R. Ajlouni, J. F. Laffoon, and J. J. Warren, "Effect of a fluoride-releasing self-etch acidic primer on the shear bond strength of orthodontic brackets," The Angle Orthodontist, vol. 72, no. 3, pp. 199-202, 2002.

[60] S. E. Bishara, V. V. Gordan, L. VonWald, and M. E. Olson, "Effect of an acidic primer on shear bond strength of orthodontic brackets," American Journal of Orthodontics and Dentofacial Orthopedics, vol. 114, no. 3, pp. 243-247, 1998.

[61] T. Grünheid and B. E. Larson, "Repeated bracket bonding: conventional or self-etching primer?," Journal of the World Federation of Orthodontists, vol. 3, no. 3, pp. 102-105, 2014.

[62] P. Spencer, Q. Ye, J. Park et al., "Adhesive/dentin interface: the weak link in the composite restoration," Annals of Biomedical Engineering, vol. 38, no. 6, pp. 1989-2003, 2011.

[63] B. Wang, N. Zhang, X. Wang et al., "Novel self-etch adhesive with antibacterial and protein-repellent functions to prevent enamel demineralization," Dental Materials Journal, vol. 37, no. 6, pp. 904-911, 2018.
[64] R. Müller, A. Eidt, K. A. Hiller et al., "Influences of protein films on antibacterial or bacteria-repellent surface coatings in a model system using silicon wafers," Biomaterials, vol. 30, no. 28, pp. 4921-4929, 2009.

[65] T. Lamper, N. Ilie, K. C. Huth, I. Rudzki, A. Wichelhaus, and E. Paschos, "Self-etch adhesives for the bonding of orthodontic brackets: faster, stronger, safer?," Clinical Oral Investigations, vol. 18, no. 1, pp. 313-319, 2014.

[66] I. R. Reynolds, "A review of direct orthodontic bonding," British Journal of Orthodontics, vol. 2, no. 3, pp. 171-178, 1975.

[67] J. H. Lee, A. El-Fiqi, J. K. Jo et al., "Development of long-term antimicrobial poly(methyl methacrylate) by incorporating mesoporous silica nanocarriers," Dental Materials, vol. 32, no. 12, pp. 1564-1574, 2016.

[68] F. Lin, L. Yao, H. Sun, Z. Ni, and M. Zheng, "A feasible method to improve adherence of Hawley retainer in adolescent orthodontic patients: a randomized controlled trial," Patient Preference and Adherence, vol. 9, pp. 1525-1530, 2015.

[69] N. J. A. Jepson, P. J. Moynihan, P. J. Kelly, G. W. Watson, and J. M. Thomason, "Caries incidence following restoration of shortened lower dental arches in a randomized controlled trial," British Dental Journal, vol. 191, no. 3, pp. 140-144, 2001.

[70] S. Altarawneh, S. Bencharit, L. Mendoza et al., "Clinical and histological findings of denture stomatitis as related to intraoral colonization patterns of Candida albicans, salivary flow, and dry mouth," Journal of Prosthodontics, vol. 22, no. 1, pp. 13-22, 2013.

[71] W. Kohnen and B. Jansen, "Polymer materials for the prevention of catheter-related infections," Zentralblatt für Bakteriologie, vol. 283, no. 2, pp. 175-186, 1995.

[72] R. S. Nohr and J. Gavin Macdonald, "New biomaterials through surface segregation phenomenon: new quaternary ammonium compounds as antibacterial agents," Journal of Biomaterials Science, Polymer Edition, vol. 5, no. 6, pp. 607619, 1994.

[73] A. E. H. Shearer, J. S. Paik, D. G. Hoover, S. L. Haynie, and M. J. Kelley, "Potential of an antibacterial ultravioletirradiated nylon film," Biotechnology and Bioengineering, vol. 67, no. 2, pp. 141-146, 2000.

[74] N. Kawabata and M. Nishiguchi, "Antibacterial activity of soluble pyridinium-type polymers," Applied and Environmental Microbiology, vol. 54, no. 10, pp. 2532-2535, 1988.

[75] L. Cao, X. Xie, B. Wang et al., "Protein-repellent and antibacterial effects of a novel polymethyl methacrylate resin," Journal of Dentistry, vol. 79, pp. 39-45, 2018.

[76] A. Yang, D. Zhao, Y. Wu, and C. Xu, "Effect of polyimide addition on mechanical properties of PMMA-based denture material," Dental Materials Journal, vol. 36, no. 5, pp. 560$565,2017$. 


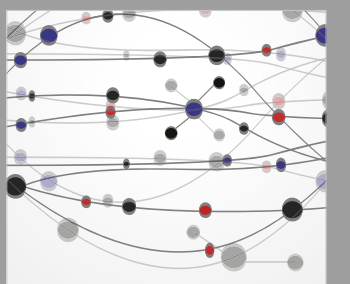

The Scientific World Journal
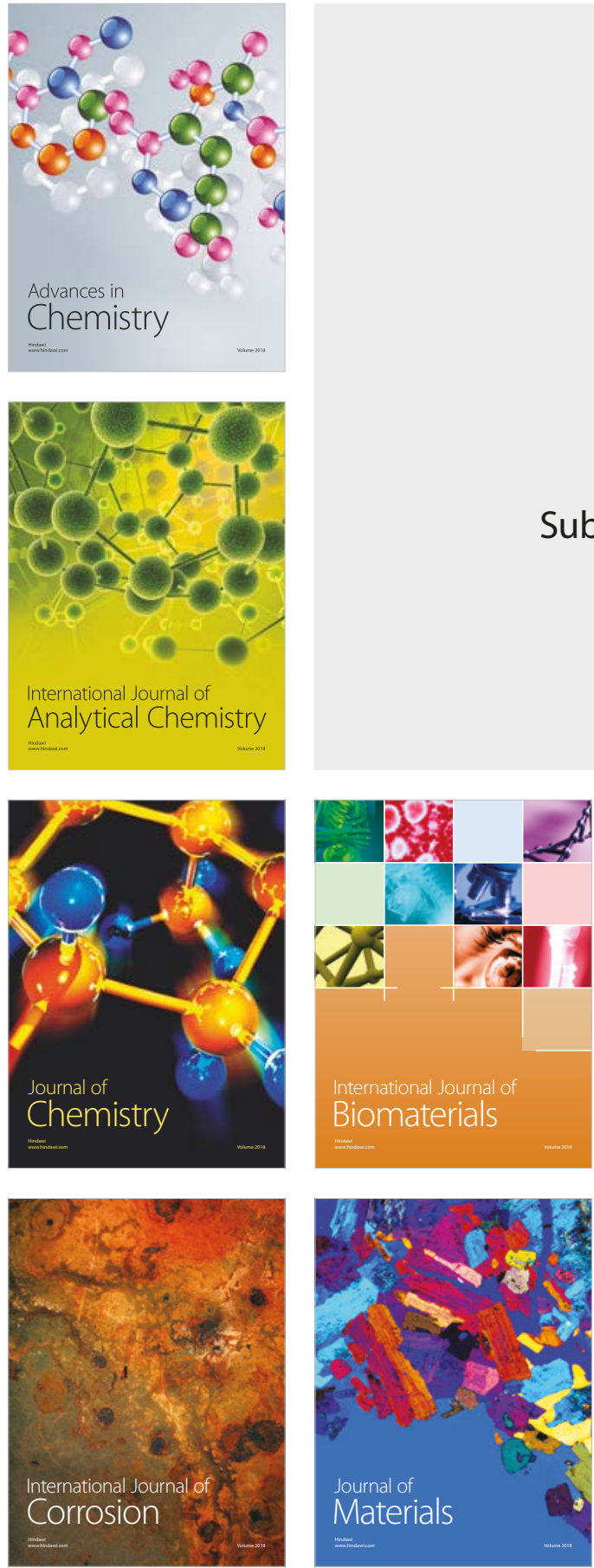

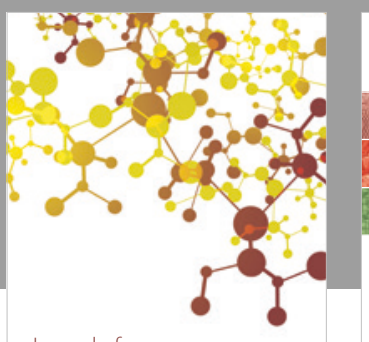

Journal of

Applied Chemistry
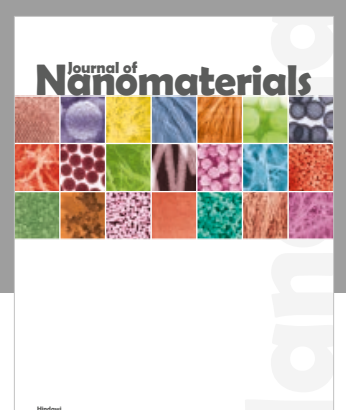

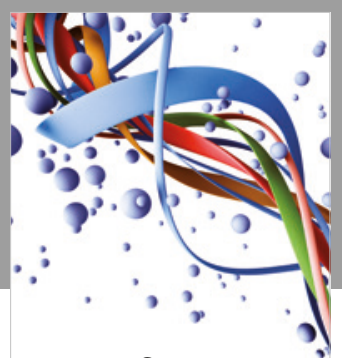

Scientifica

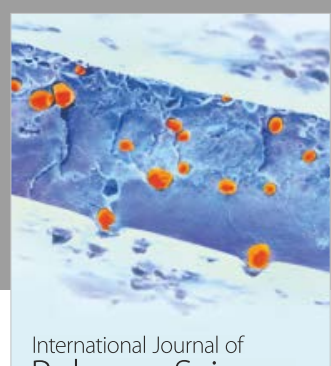

Polymer Science

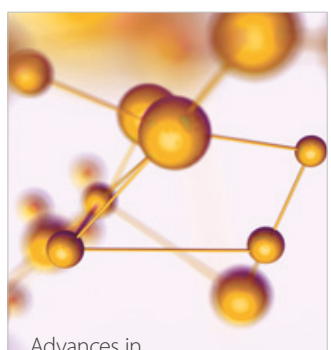

Physical Chemistry
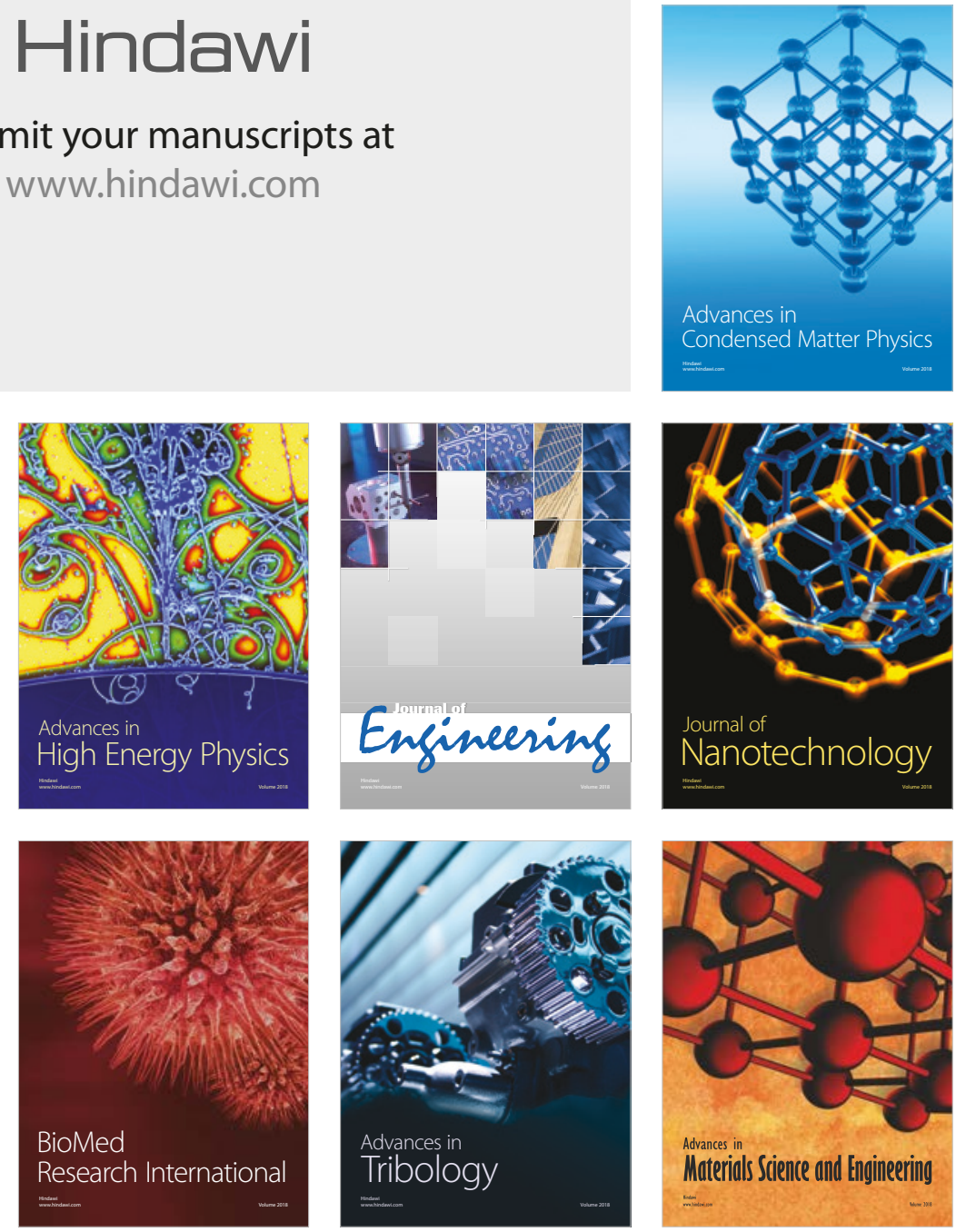